\title{
JOB CREATION AND DESTRUCTION
}

A Review of S. J. Davis, J. C. Haltiwanger, and S. Schuh, Job Creation and Destruction, MIT Press, Cambridge, MA and London, 1996.

With unemployment at historically high levels in many OECD countries, increased job creation has risen to the top of the policy agenda for many western governments--but how can this be achieved? The importance of job creation (and destruction) in an economy cannot be overstated. Labour is organized and reallocated among firms through the job creation and destruction process to create wealth and income, but jobs also play the major role in income distribution. For most families, the earnings which jobs generate are the basis of their incomeand income distribution has been a topic of intense interest in recent years. Furthermore, job destruction can lead to involuntary worker separations and possibly substantial adjustment costs for individuals.

This well-written book assembles much of the empirical work written on job creation and destruction. It is well laid out and accessible to both specialists and generalists, and significantly advances our understanding of the dynamics of job gain and loss. Simple and very useful examples are often presented to clarify measurement concepts, thus increasing the accessibility of the results and the methods.

What is meant by "job creation and destruction?" The traditional measure of net employment change at an industry level indicates that manufacturing employment fell 1.1 percent annually (on average) between 1973 and 1988 in the U.S. This leaves the impression that plants were losing employment over the period, and that the change was relatively small. In fact, 10.3 percent of jobs were lost each year (on average), and 9.1 percent were created, as some plants expanded, and others contracted. There is a high degree of reallocation and restructuring of both jobs and labour among plants and firms that is masked by the aggregate net statistics on which we have traditionally relied. This book therefore focuses on employment change at the level of the plant (or firm) rather than at a more highly aggregated level, such as the industry. An expansion of employment in a plant (or the birth of a new plant) is job creation, while contraction in employment in some other plant (or the death of a plant) is seen as job destruction. For many purposes this is a more informative way of looking at job creation.

Research on the dynamics of job creation and destruction began in the late 1970 s, and has been very empirical in nature, being driven primarily by the availability of longitudinal data sources on plants and companies. As new data sources increased in number in the $1980 \mathrm{~s}$, so too did research in this area. This book presents research for the U.S. manufacturing sector using primarily the Longitudinal Research Database maintained at the U.S. Census Bureau's Center for Economic Studies and addresses a broad range of issues. The macro-economic 
implications of job creation and destruction over the business cycle, and the structure of job creation (whether it is concentrated among few firms or widespread, and its allocation between small and large companies) receive attention, but the focus is often on the micro aspects of job creation. At the level of the individual plant do we know what is associated with rapid job creation or destruction? What distinguishes a rapidly expanding plant from a declining one? What are the economic and policy implications?

Part of the dynamism of capitalism is its continual reallocation of resources, but does this happen primarily during recessions or expansions? This is one of the issues the book addresses. Do establishments adjust to downturns primarily through a drop in job creation, or an increase in job destruction? The authors find that recessions in U.S. manufacturing are characterized by a sharp increase in job destruction, and only a mild slowdown in job creation; job destruction rates exhibit greater cyclical variation than job creation rates. Overall job reallocation among plants increases during recessions, primarily as the result of increased job destruction in many plants. However, not all firms respond in the same manner during a downturn, and some account of this heterogeneity is necessary if we are to better understand cycles. In addition, the restructuring that takes place during recessions, as indicated by the increase in job reallocation, is not currently well accounted for in the literature.

Other work shows that this increase in job turnover in recessions is observed in a number of countries including Canada. However, there is not an international consensus on whether job reallocation is pro or countercyclical. A review by the OECD on job turnover demonstrated no conclusive pattern across many developed economies (OECD, 1994). Results for the U.S manufacturing sector may differ from some other sectors and countries.

As well, one can look to worker flows rather than job gains and losses to assess whether a structural reallocation of resources occurs primarily during recessions or expansions. As the authors note, the reallocation of workers over the cycle displays a somewhat different pattern from the reallocation of jobs. Both American (Akerloff, Rose, and Yellen, 1988) and Canadian (Picot and Baldwin, 1990) work indicates that worker reallocation is not countercyclical; overall worker turnover falls during recessions, although job turnover was found to increase. Fewer workers both leave and enter firms in recessions. Hiring falls in recessions, as do permanent separations from firms (since quits fall more than permanent layoffs rise). Worker flows data suggest that resources are reallocated among firms at a much higher rate during expansions. It may be that jobs are lost in some companies during downturns, and replaced in other firms during expansions, at which time worker reallocation takes place. Thus, the reallocation process is likely driven by economic events occurring in both recessions and expansions.

As well, the entry and exit of plants has important impacts on structural change over time or among regions. In Canada, Baldwin and Gorecki (1990) found that the variation was primarily in the entry rates of plants, not exit rates. They concluded that "an industry's net employment rate varies over time primarily because of differences in yearly entry rates, not exit rates." Inter-regional variation in job growth is due more to differences in entry and job creation rather than to 
difference in exits and job loss (as observed in a number of countries). Thus, they conclude policies focusing on the creation of new companies, rather than jobretention policies, are likely to be most productive in promoting structural change that will lead to employment gains.

In a related chapter the authors ask if the very large amount of worker turnover observed in developed economies is accounted for by the supply side of worker preferences or by demand side influences on plants, leading to job creation and destruction? They conclude that from one-third to one-half of worker reallocation is induced by job reallocation associated with demand side changes. The book also contains a very interesting section on worker flows among employment, unemployment and not-in-the-labour-force, how this varies over the cycle, and its association with job turnover. One very nice feature of this work is that it integrates worker and job flows, and discusses the implications of the reallocation of jobs for the movement of workers.

The book tackles the long standing debate on the role of small firms in job creation. The statistical observation by the American economist Birch in the 1970s that small firms create a disproportionate share of jobs has probably had as much impact on public policy as any single observation about job creation. It has also been one of the most controversial. In this book the authors summarize their earlier research that indicates that (at least for the U.S. manufacturing sector) this is not true. They argue that a combination of poor measurement technique and the improper use of data led to this result. Correcting for these shortcomings, they find no relationship between plant size and net job creation rates in manufacturing.

When this research was replicated for the Canadian manufacturing sector, measurement issues did influence the results, but even after the corrections were applied, small Canadian manufacturing plants created a disproportionate share of jobs (Baldwin and Picot, 1995). For whatever reasons, results differ for the Canadian and American manufacturing sectors. Small manufacturing plants in Canada appear to be quite dynamic. However, while small manufacturing plants in Canada are increasing their employment shares substantially, the same is not true for output. Large firms have higher labour productivity and the gap between large and small manufacturing plants has widened (as has the relative wage gap). Small manufacturing plants have been creating a disproportionate share of jobs, but relative productivity and relative wages have been falling (Baldwin, 1996). Since national differences appear to be important, it would be interesting to see what has been happening to relative productivity and wages in the U.S., where the relative job creation prowess of small firms appears to be less.

Overall, it is births that appear to account for the differential (net) job creation rates between the small and large firm sectors in Canada (Picot and Dupuy, 1996; Brander et al., 1996). Existing small and large firms appear to grow at about the same rate, but the small firm sector displays faster job growth because births are included in the aggregate count. This suggests that policies focusing on the creation of new firms are important, and that the entrepreneurial spirit that leads to births plays a very important role in the job creation process in Canada.

However, the authors of the book argue that even if job creation were disproportionately concentrated in the small firm sector, this does not necessarily 
mean small firms should receive preferential policy treatment. They argue that there is no market failure that the preferential policies address. As well, much of the research on job creation in small and large firms has been missing an essential question. Even if a particular sector is demonstrating rapid growth, it does not mean that one can maximize the effects of preferential treatments or government expenditures by concentrating on that sector. A one dollar expenditure may have more (job creation) effect elsewhere. In addition, the jobs created in small firms are less desirable across a number of dimensions (as indicated by lower wages, lower fringe benefits, lower job stability), and there is evidence that the wage differential between jobs in small and large firms may be increasing. The creation of new firms does seem like a promising area on which to focus attention, however, given its role in both job creation and the structural adjustment process. The authors bring the question of public policies for small firms front and centre once again, and the controversy will no doubt continue.

The work on job creation by firm size, among sectors and over the business cycle refers to "average" job creation among expanding plants (or firms), and average job destruction among declining plants. However, there are few average plants, and to think in this way is potentially misleading. Not all small firms create large numbers of jobs ... the majority have little change in employment or lose jobs in any given year. The same can be said for large firms, or firms in general. Knowing that a specific firm is small (or large), or in a particular industry, will tell us little about its job creation potential if such job creation is highly concentrated among relatively few firms, which seems to be the case.

Most job creation and destruction is associated with dramatic increases or decreases in employment. Two-thirds of job creation or destruction took place in plants that expand or contract by 25 percent or more over the year, or involved a birth or death. Most job creation and destruction occurs among relatively few plants that grow (or contract) at rates well above average. The U.S. manufacturing data fits with other results for the U.K. (Blanchflower and Burgess, 1994) and economy-wide results for Canada (Picot and Dupuy, 1996). For example, the Canadian results indicated that almost half of job gain and loss in each size category was accounted for by around 5 percent of companies. Thus, average rates of job creation and destruction can be quite misleading, as most of the action takes place among relatively few plants or companies. Knowing a plant or firm's size or industry, tells one little about the job creation prowess of that firm, since only a few firms create large numbers of jobs in any given year.

One of the most interesting findings of this book is that the explanations of market share and job reallocation that generally receive much of the attention explain relatively little. Discussion of reallocation often focuses on changing industrial structure, the impact of international trade, and changing consumption patterns. To be sure, such restructuring results in the reallocation of labour demand, positively affecting companies in the expanding sector, and negatively influencing those in others. However, although such reallocation among sectors is important, it is small compared to the within-sector reallocation of jobs, labour and market share, no matter whether the sectors are defined by industry, region, plant age, size, capital intensity, trade, etc. In short, outcomes are very heterogeneous within 
commonly classified groups in the U.S. as elsewhere (see Baldwin and Gorecki, 1990).

This result also helps to explain why permanent layoffs among workers (in the Canadian economy at least), tend to be high during both economic expansions and recessions, and why some industries with high employment growth can have layoff levels that are well above layoff rates in industries in structural decline. It also explains why permanent layoffs are heavily concentrated among small firms, where the job turnover is much greater. With most job reallocation occurring within industries and associated with idiosyncratic features of the particular plant, rather than being caused by changes in aggregate demand or industrial variation in demand, it is likely that permanent layoffs are driven to a great extent by this intra-industry job reallocation (Picot, Lin, and Pyper, 1996).

If job creation and destruction is dominated by idiosyncratic features of the plant about which we know little, rather than the more easily observable factors such as industry, region, employer size or age, foreign competition, etc., targeted policies that provide preferential treatment based on firm size, industrial sector or other dimensions will have serious problems. This book argues that targeted policies are difficult to establish because of the tremendous heterogeneity of outcomes, and our ignorance regarding "what works." As well, such policies (e.g. the preferential treatment of small firms) may inadvertently impede the allocation of jobs and workers to their highest value uses and are difficult to evaluate because of very different policy responses among businesses, and the high degree of heterogeneity of outcomes.

However, heterogeneity of results after controlling for the effects of known and measurable factors is not restricted to research on job dynamics. When running wage equations that attempt to explain the determinants of wage levels, the standard human capital variables such as education and work experience typically explain less than half of the variance. This does not prevent us from telling our children that education is one of the best means of increasing their chances of getting good, high paying jobs. Education is not a guarantee but it does have an effect, even if other unmeasured factors, such as work habits and motivation also influence wage rates. Hence, while the observation that idiosyncratic effects dominate known effects in terms of job creation is very powerful and important, it does not mean that one cannot observe effects which, while leaving much unexplained, are nonetheless important (such as the business acumen, knowledge and experience of owners/managers, the degree of innovation, marketing, technology and Human Resource practices).

The chapter on economic and policy implications of the work is a very welcome addition. The authors note that high rates of job creation and destruction underscore the importance of having a flexible workforce able to adapt and adjust in terms of location and skill requirements. Current data would suggest that the workforce is probably quite flexible, as indicated by worker mobility-for example about one-fifth of Canadian workers change companies in any given year. Interindustry mobility is already very high (although some would argue inter-regional mobility is too low). Policies that support and encourage workers in this process of this adjustment are important in dynamic economies, since society as a whole benefits from such flexibility and reallocation of labour. However, the authors 
argue that "cross-industry differences in gross job flow behaviour do not support the view that greater openness to international trade undermines job security by exposing American firms and workers to additional sources of disturbances."

The major shortcoming of the book is beyond the control of the authors; most of the results refer to the manufacturing sector in the United States (for which the necessary data sources currently exist). While the authors cite many international works, a chapter comparing international findings to similar work in Canada, France, Germany and Sweden and elsewhere would be an excellent addition. The OECD has attempted to integrate data sources from member countries and assess the policy implications of the work (OECD, 1994, 1996), but there are, however, major difficulties in developing comparable data sources among countries. One such comparison (co-authored by one of the present authors) confirmed that, at least for the manufacturing sectors in Canada and the U.S., many of the characteristics of job creation and destruction are quite similar. (Baldwin, Dunne, and Haltiwanger, 1994).

The research reported in the book was possible because of the creation of longitudinal plant level data sources. Just as the development of longitudinal household data sources allowed labour economists to acquire a new and revealing look at the dynamics of unemployment, poverty, and the effects of job loss, so too the development of longitudinal plant or company data sources provides new insights into the dynamics of job creation and destruction. This work has fundamentally altered the way in which we think about job creation. In the U.S., this has been possible because of the Longitudinal Research Database (LRD) created by Bob McGuckin and his colleagues at the Bureau of the Census.

By debunking many stereotypes regarding the magnitude, time trends and location of job gains and losses this book makes a very large contribution to economics. Our view of the job creation process has been fundamentally altered. The results raise many questions. Why is job creation greater in some firms than others? Does a more regulated labour market entail a significant difference in the dynamic nature of job creation and destruction between countries? Preliminary evidence from the book, where international evidence is presented, suggests not, although the evidence is in no way conclusive.

The development of both theory and policy is advanced by interpreting the results of these empirical findings in innovative ways, as the authors often do. However, existing data sources are limited. They have given us a good understanding of the magnitude of the dynamics of job creation and destruction, but these sources do not explain the determinants. Basic questions remain regarding the quality of the jobs created and destroyed, the association with technological change, and the role of contracting out and temporary work. New longitudinal data sources that link information on the workforce, the business itself, and the market in which it functions were called for in a review of job creation and destruction research by Blanchflower (1996), and by the authors of this book. It is time to integrate the two survey worlds that have existed quite independently in most countries, the household (worker) survey and the business (company and plant) survey. A data source that simultaneously provided information on firms and workers at the micro level would open new areas of research, some related to the job creation and destruction process. 
There is a need to be able to link, in the same micro-database, events occurring in establishments (e.g. jobs created and lost, output and payroll, implementation of technologies, training offered, births and deaths of firms, types of markets in which the firm competes, degree of competition, H.R. practices, etc.) and characteristics and outcomes for workers (e.g. wages rates, hours worked, training taken, human capital held, technologies used, job characteristics, flows into and out of the firm, and experience following a separation). Ideally the data source would be longitudinal, so that changes in establishment events or worker characteristics could be associated with changes in outcome variables. Such a data set would mean that research on worker outcomes (e.g. wages, hours, workers flows, training taken, technologies used, etc.) could now incorporate explanations that included events in firms, such as the adoption of technologies, the type of market in which the firm competes, H.R. practices of the firm, etc. instead of having to depend only on human capital and other characteristics of the workers because only worker micro-data are available. Workers' outcomes could be related not only to supply side factors, but demand side as well. Similarly, one could examine how outcomes for plants, such as job creation and destruction, depend on characteristics and activities of the workers. This is rarely possible in micro-data analysis.

In Canada there have in the past been "pilot projects" where workers and firms were linked at the micro level (e.g. Osberg et al., 1986). The Business and Labour Market Analysis Division of Statistics Canada has also recently piloted a matched worker-firm survey that is very similar to that just described (called the Workplace and Employee Survey). The intention is to make it fully operational in 1998. The authors of this book have done pathbreaking work, but they leave us with a puzzle - how to explain the heterogeneity of outcomes. Hopefully, new data sources should allow the results of this book to be extended.

Garnett Picot

Statistics Canada

\section{REFERENCES}

Akerlof, G., A. Rose, and J. Yellen, Job Switching and Job Satisfaction in the U.S. Labor Market, Brookings Papers on Economic Activity, Brookings Institute, Washington, DC, 1988.

Baldwin, J., Were Small Producers the Engine of Growth in the Canadian Manufacturing Sector in the 1980s, Analytical Studies Branch Research Paper no. 88, Statistics Canada, Ottawa, 1996. -, and P. Gorecki, Structural Change and the Adjustment Process, Economic Council of Canada, Ottawa, 1990.

, T. Dune, and J. Haltiwanger, A Comparison of Job Creation and Job Destruction in Canada and the United States, NBER research paper, 1994.

— and G. Picot, Employment Generation by Small Producers in the Canadian Manufacturing Sector, Journal of Small Business Economics, 1995.

Blanchflower, D. G., Job Creation and Loss: Research Questions Arising from the Use of Establishment Based Data, in Job Creation and Loss, OECD, Paris, 1994.

and X. X. Burgers, Job Creation and Destruction in Britain, 1980-90, Discussion Paper no. 912, Centre for Economic Policy Research,

Brander, J., K. Hendricks, R. Amit, R. Arend, T. Ross, and D. Whistler, The Dynamic Structure of the Small and Medium-Sized Enterprise Sector, Discussion paper prepared for the Entrepreneurship and Small Business Office, Industry Canada, 1996.

OECD, Job Gains and Job Losses in Firms, in Employment Outlook, OECD, Paris, 1994. 
Job Creation and Loss, in Analysis Policy and Data Development, OECD, Paris, 1996.

Osberg, L., R. Apostle, and D. Clairmont, The Incidence and Duration of Individual Unemployment : Supply Side or Demand Side?, Cambridge Journal of Economics, Vol. 10, No. 1, pp. 13-34, March 1986.

Picot, G. and R. Dupuy, Job Creation by Company Size Class: Concentration and Persistence of Job Gains and Losses in Canadian Companies, Journal of Small Business Economics, 1996.

- and J. Baldwin, Patterns of Quits and Layoffs in the Canadian Economy, Canadian Economic Observer, October and December, Statistics Canada, Ottawa, 1996.

-, Z. Lin, and W. Pyper, Permanent Layoffs, An Overview and Longitudinal Analysis, Analytical Studies Branch Research Paper, Statistics Canada, Ottawa, 1997. 